(C) 1981. The Genetical Society of Great Britain

\title{
GENETIC VARIATION IN SPACE AND TIME IN A POPULATION OF PONDEROSA PINE
}

\author{
Y. B. LINHART, J. B. MITTON, K. B. STURGEON and M. L. DAVIS \\ Department of E.P.O. Biology, University of Colorado
}

Received 1.vi.79

\section{SUMMARY}

\begin{abstract}
The genetic structure of a population of Pinus ponderosa was studied using seven electrophoretically-detectable protein loci. This population is composed of six groups of trees, which differ significantly from each other in their genetic constitutions. The results imply that the population is composed of groups of individuals assembled into genetically-related family units. Whenever such family clusters have been documented in other studies, marked inbreeding has also been noted as a consequence. In this population, no inbreeding is detectable. The groups also differ from one another in several characteristics which have genetic consequences within the population as a whole. These characteristics include age structures, seed output, level of infestation by woolly aphids and extent of damage by deer browsing. The population was also divided into four age classes which do not differ markedly from one another in their genetic characteristics. This suggests that genetic differentiation in time is much less marked than differentiation in space.
\end{abstract}

\section{INTRODUCTION}

AlthOUGH biologists have long been aware of the variability present within species, the mechanisms by which such variability is generated and maintained in large continuous populations are still not clearly understood (Endler, 1977; Lewontin, 1974). To a great extent this question reflects our ignorance of the spatial and genetic structure of continuous populations and of the relative contributions to population differentiation of varying selection pressures, family structure and gene flow. Our knowledge is particularly scanty when it comes to long lived species such as forest trees whose long generation times have been an obstacle to genetic studies. Yet, forest trees merit serious study in this context, particularly since a recent review of patterns of genetic variation in plants has shown that populations of forest trees seem to maintain higher levels of variability than do those of shorterlived species (Hamrick et al., 1979).

Early theoretical studies assumed that continuous populations were spatially fluid, panmictic and genetically quite homogeneous; these assumptions have been contradicted by detailed field studies of both animals (reviewed in Selander et al., 1969; Ehrlich et al., 1975; Jones, 1973) and plants (Epling and Dobzhansky, 1942; Bradshaw, 1972; Schaal, 1975). These field studies suggest that many extensive populations, particularly in plants, consist of numerous, semi-isolated demes. This structure may be due to two phenomena: diversifying selection may produce differentiation among populations in heterogeneous environments and/or isolation by distance may result from highly restricted gene flow. The evidence for the role of heterogeneous environments in producing genetic differentiation by means of disruptive selection is extensive (see reviews by Bradshaw, 1972; 
Endler, 1977). The evidence of restricted gene flow in plants is also extensive, and has led to the assumption that there exist, within continuous populations, small clusters of genetically related individuals (Bradshaw, 1972; Levin and Kerster, 1974). However, the existence of these clusters has seldom been documented. Furthermore, the early, largely anecdotal, assumptions about panmixia and genetic homogeneity persist in the literature especially with regard to wind-pollinated species which occur in large, continuous stainds. Even Endler (1977, p. 28) states that some grasses and conifers are "exceptions to the general deme pattern of species distribution",

The results presented here represent one aspect of a larger study designed to characterize the genetic and ecological features of the population architecture of ponderosa pine, Pinus ponderosa Laws., in the Front Range of the Colorado Rocky Mountains. Initial studies revealed that genetic differentiation has occurred in forests of ponderosa pine and that it is associated with erivironmental heterogeneity (Mitton et al., 1977, 1980). In this paper, we increase the resolution of these analyses to further document the magnitude of micro-geographic differentiation possible within a typical, undisturbed, continuous stand of a wind-pollinated out-crossing forest tree. The site studied is particularly suitable for this analysis because the population is not very dense, and can be mapped and sub-divided spatially into relatively discrete groups among which genetic and ecological characters are compared. In addition all trees were aged and genetic comparisons were made among age classes in order to ascertain the relative levels of genetic heterogeneity in space and time.

\section{MAterials AND METHOds}

This population is located on the South-facing slope of the entrance to Boulder Canyon, near the town of Boulder, Colorado, U.S.A., at an elevation of $1738 \mathrm{~m}$. The population comprises all the individuals within an area of approximately two hectares, which is undisturbed by human activity and is located within a ponderosa pine belt covering the lower slopes of the Rocky Mountains in this region. There are no other woody species within the study plot. All ponderosa pine (239 individuals) were permanently tagged and mapped. The following data were recorded for the 217 individuals capable of reproducing within the population, i.e., all trees over 30 years of age: genotype for seven different protein loci, age, diameter, reproductive output, susceptibility to infestations by woolly aphids (Pineus coloradensis) and browsing by deer (Odocoileus hemionus).

\section{(i) Genetic analyses}

For 217 of these individuals, which comprise all of the population except 22 small saplings or severely stunted individuals, we have recorded genetic variation at the following protein loci: peroxidase (PER); colorimetric esterase (CE); fluorescent esterase (FE); glutamate dehydrogenase (GDH), phosphohexose isomerase (PHI) and two loci of phosphoglucomutase (PGM-1, PGM-2). In this population, there are 2 alleles at GDH and 3 alleles at all other loci. For explanations of genetic analyses and starch gel electrophoretic methods see Mitton et al., $(1977,1979)$. Allele frequenc:es 
at all loci were compared among spatially distinct groups of trees (see below) and also among four major age classes. Heterogeneities of allele frequencies were tested with the Chi-square test as described by Workman and Niswander (1970).

The genetic structure of the subpopulations was analysed using several statistics found to be useful in previously published studies on other species of plants. Use of the same statistics provides the opportunity for comparisons of the genetic architecture of these populations. The first of these methods are Wright's $F$ statistics (Wright, 1965). These statistics are used here to describe three phenomena. $\bar{F}_{I S}$ represents the correlation between uniting gametes within clusters and represents the mean deviation of genotypic proportions from Hardy-Weinberg expectations. A positive $\bar{F}_{I S}$ is associated with deficiencies of heterozygotes and suggests inbreeding; a negative $\vec{F}_{I S}$ indicates excesses of heterozygotes. For any one cluster

$$
F_{I S}=1-H_{0} / H_{e}
$$

where $H_{0}$ denotes the numbers of heterozygotes observed and $H_{e}$ denotes the number of heterozygotes expected in that cluster. The weighted mean of the $F_{I S}$ for all clusters is $\bar{F}_{I S} . F_{S T}$ represents the correlation between random gametes within a given cluster relative to gametes within the whole population. This value is used to detect the amount of differentiation between subpopulations. For any locus with two alleles, $F_{S T}=\sigma_{p}^{2} \sqrt{\bar{p} \bar{q}}$ where $\bar{p}$ and $\bar{q}$ are the weighted mean frequencies of the two alleles in the whole population and $\sigma_{p}^{2}$ is the weighted mean of the squared deviations of gene frequencies of individual clusters from the mean gene frequency. For loci with multiple alleles, covariances between specific pairs of alleles need to be considered (Nei, 1965; Li, 1969), and $F_{S T}=-\sigma_{j k} / \bar{P}_{j} \bar{P}_{k}$ where $\sigma_{j k}$ is the covariance between alleles $j$ and $k$, and $\bar{P}_{j}$ and $\vec{P}_{k}$ are the mean frequencies of these alleles in the whole population.

$F_{I T}$ represents the correlation between uniting gametes, and therefore the fixation index, within the whole population. $F_{I T}$ can be calculated using two methods. The direct method is $F_{I T}=1-H_{0} / H_{e}$ where $H_{0}$ is the observed number of heterozygotes in the whole population and $H_{e}$ is the expected number, based on mean allele frequencies. The indirect method is $F_{I T}=\bar{F}_{I S}+\left(1-\bar{F}_{I S}\right) F_{S T}$ as shown by Wright (1951). This method assumes that differentiation between subpopulations is random.

The extent of differentiation between clusters, using all loci simultaneously was also quantified using measures proposed by Nei (1972). The degree of identity between any two clusters is calculated by $I=J_{x y} / J_{x} J_{y}$ where $J_{x}$ and $J_{y}$ are the probabilities of choosing a pair of identical alleles from populations $x$ and $y$ and $J_{x y}$ is the probability of choosing a pair of identical alleles, one from population $X$ and the other from population $Y$. The distance between any two clusters is $D=-\log _{e} I$.

The total variation present in this population was partitioned into within groups and between groups components, using two methods commonly employed in other such studies. One is the Shannon information index, $H$ where

$$
H=-\sum_{i=1}^{n} p_{i} \ln p_{i}
$$


and $n$ is the number of alleles at a given locus and $p_{i}$ is the frequency of the $i$ th allele (Lewontin, 1972). The other is a method developed by Nei (1977) as a modification of Wright's $F$ statistics. The total diversity is partitioned into within and among subunit components. The total variation $\vec{H}_{T}$ is equal to the expected heterozygosity, averaged over all loci of the population at Hardy-Weinberg equilibrium.

$$
\bar{H}_{T}=\bar{H}_{S}+\bar{D}_{S T}
$$

where $\vec{H}_{S}$ is the weighted average of expected heterozygosities at all loci in all subunits or groups. $\bar{D}_{S T}$ is a measure of the diversity among subunits. In addition one can estimate the magnitude of interpopulation differentiation $G_{S T}$ relative to the total variation by calculating

$$
G_{S T}=\bar{D}_{S T} / \bar{H}_{T}
$$

Nei (1977) noted that $G_{S T}$ and Wright's $F_{S T}$ can be equivalent.

\section{(ii) Life history analyses}

The ages of the trees were estimated from increment cores taken at $30-50 \mathrm{~cm}$ above ground, and diameters were measured for these trees at the same height. Differences in age and size structure among groups were tested using an analysis of variance. In addition, the genetic characteristics of four major age classes present within this population were compared.

Reproductive output was recorded for these trees in 1977 and 1978. Production of male strobili was noted on a scale of $1-3$, with $0=$ no strobili, $1=1-5$ branch terminals with strobili, $2=6-20$ branches with strobili and $3=$ more than 20 branches with strobili. Female cone production was recorded by counting all mature cones, omitting the obviously aborted or diseased ones, in late summer 1977 and 1978. Because of the small size of these trees (usually 10-15 m) we were able to make an estimate of all cones produced. Differences among groups were tested with Chi-square tests.

Presence or absence of woolly aphid colonies on lower branches was recorded for all trees, and damage by deer browsing was recorded on 105 trees with branches low enough to the ground to be reached by deer. Deer are common in this stand because a small herd has its winter range in the area. They eat ponderosa pine routinely and can defoliate lower branches completely. Data were collected on this defoliation by looking at 10 lower branch tips chosen randomly around the periphery on each tree and counting how many were browsed. This information was recorded in the spring of 1977 and 1978 after the winter browsing was finished and before spring needles had come out. For both kinds of animal attack, among group differences were tested with Chi-square tests. Patterns of deer browsing within the whole population were also tested for their deviation from a Poisson distribution by calculating the coefficient of dispersion (Sokal and Rohlf, 1969).

\section{Results}

The population can be subdivided into six groups of trees with relatively open spaces of $8-20 \mathrm{~m}$ between the groups (fig. 1). Such open spaces are usually devoid of trees. Of the 217 trees which are characterized genetically, 

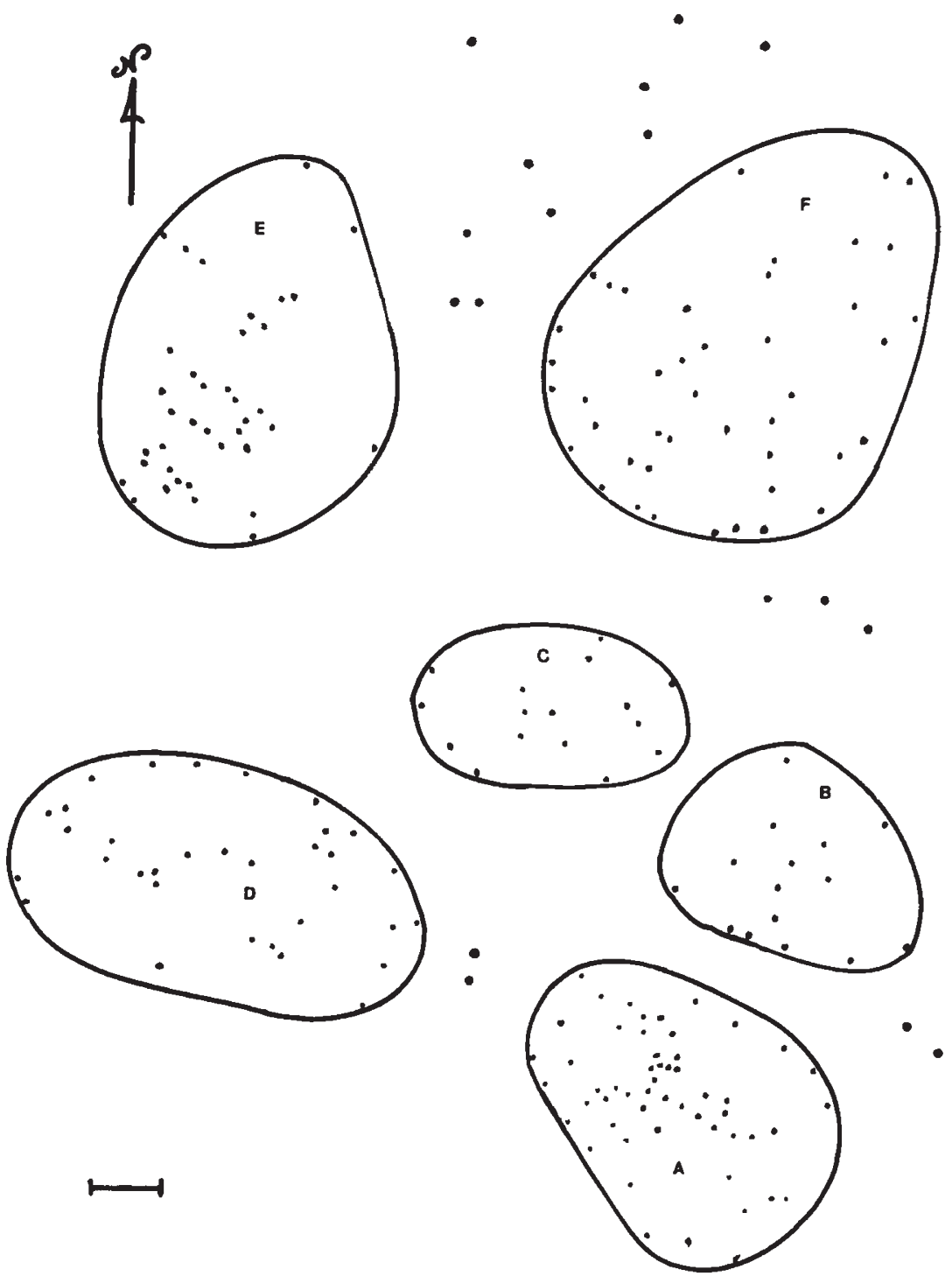

FIG. 1.-Relative positions and approximate sizes of six groups of trees in a ponderosa pine population. Individual trees are indicated as dots. Letters denote the clumps and are referred to throughout the text. The bar in lower left hand corner indicates $10 \mathrm{~m}$.

199 fall clearly into one of these six groups. The remaining 18 are located either between groups or near the periphery of the population studied and are members of groups outside the population; these trees were not considered in the analyses. The genetic characteristics of the groups are presented first, and are followed by data on several ecological attributes of the groups. 
a $\dot{0}$

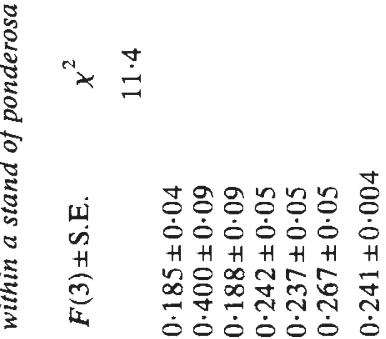

f

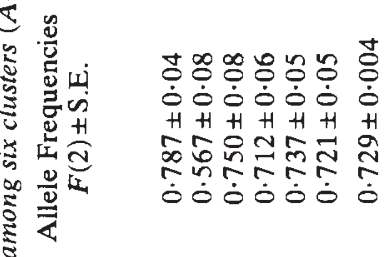

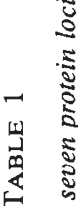

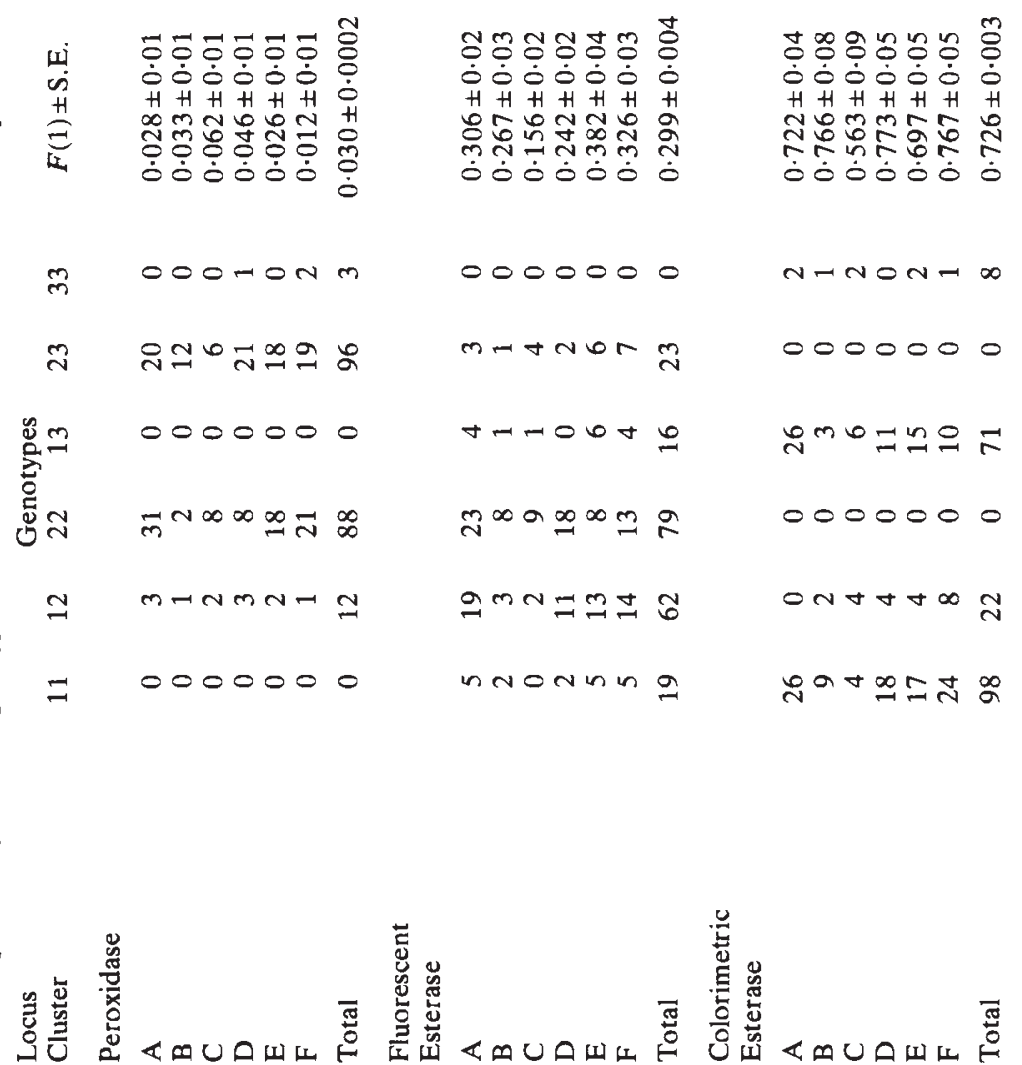

nom nom $\dot{0} \dot{0} \dot{0} \dot{0} \dot{0} \dot{0} \dot{0}$ 두요은

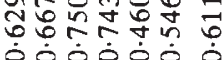
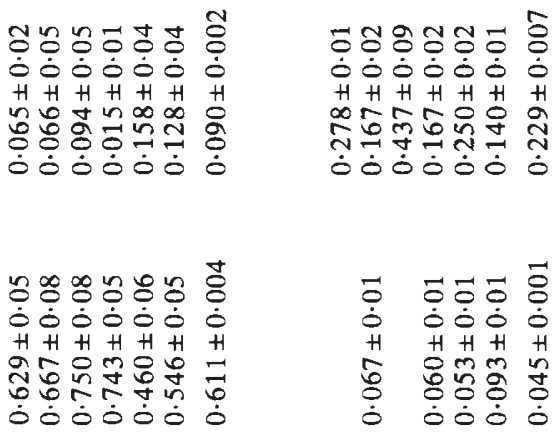

ㅎㅇㅇ용용 o 0000 สํํำธิ 过它它它

$$
\begin{array}{r}
5 \\
5 \\
5 \\
5 \\
0 \\
5 \\
5 \\
5 \\
+1
\end{array}
$$$$
\text { . }
$$ 


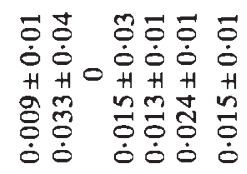

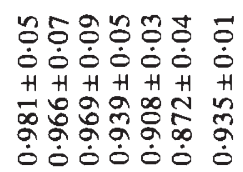
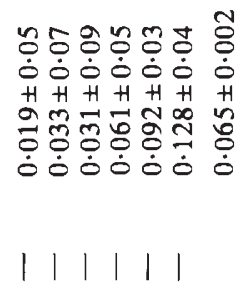

| | | | |

$1+1 \mid 1$

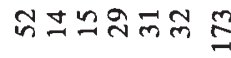

งーーナก=

0000000
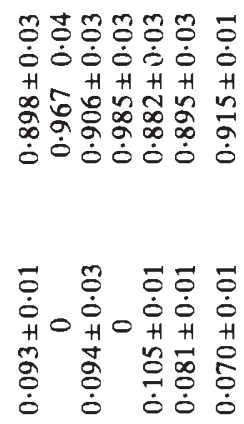

0000000

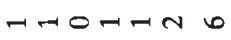

0000000

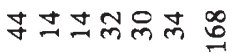

morova

ro- $0-0 \mathrm{~m}$

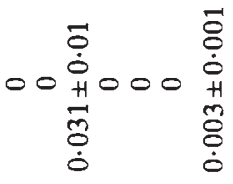

\%)

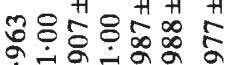
逐

$\stackrel{\text { 巳 }}{\dot{\delta}}$

m

| | | | |

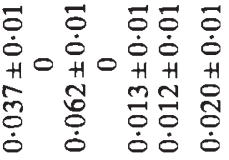

0000000

$00-000-$

0000000

ํㅡำกำ

tonOra

0000000

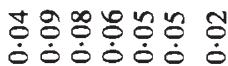
H H H H H H

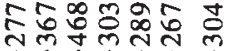
$\dot{0} \dot{0} \dot{0} \dot{0} \dot{0} \dot{0}$
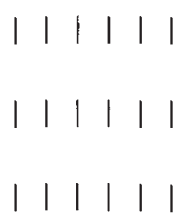

nnanAr ํำ유

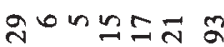

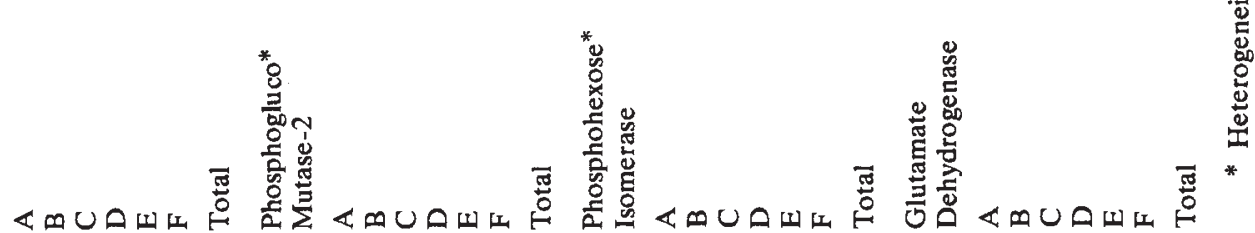


(i) Genetic structure of the population in space

The genetic characteristics of the six groups (table 1) show that there are differences in allelic frequencies among them. These differences are statistically significant for CE and FE. Nei's measures of genetic distance and genetic identity which combine the data from all seven loci are presented in table 2. The mean distances and identities between any one cluster and the

TABLE 2

Genetic Identities (below diagonal) and Distances (above diagonal) among six clusters within the Boulder Canyon population of ponderosa pine. Calculated by method of Nei (1972). Mean distance between any one cluster and all other clusters is presented below

\begin{tabular}{lccccccc} 
& \multicolumn{7}{c}{ Cluster } \\
A & A & B & C & D & E & F & \\
B & - & 0.015 & 0.017 & 0.007 & 0.006 & 0.007 & \\
C & 0.985 & - & 0.027 & 0.006 & 0.017 & 0.012 & \\
D & 0.983 & 0.973 & $-\overline{9}$ & 0.022 & 0.030 & 0.035 & \\
E & 0.993 & 0.994 & 0.979 & - & 0.015 & 0.008 & \\
F & 0.994 & 0.983 & 0.971 & 0.986 & - & 0.004 & \\
& 0.992 & 0.988 & 0.966 & 0.992 & 0.996 & - & Overall \\
& & & & & & & $\bar{X}$ \\
Mean Distance & 0.010 & 0.015 & 0.026 & 0.012 & 0.014 & 0.013 & 0.015
\end{tabular}

other five clusters are also presented. The results show that there is no obvious relationship between the physical distance separating any two clusters (fig. 1) and the genetic distance.

A summary of the genetic structure of this population using $F$-statistics is presented in table 3 . The $F_{I S}$ values are highly variable, and show that for

\section{TABLE 3}

$F$ statistics for seven loci in the Boulder Canyon population of ponderosa pine

\begin{tabular}{lrcrr} 
Locus & \multicolumn{1}{c}{$F_{I S}$} & $F_{S T}$ & Direct & Indirect \\
PER & -0.3877 & 0.0121 & -0.3300 & -0.3709 \\
FE & 0.0210 & 0.0680 & 0.0378 & 0.0880 \\
CE & -0.1607 & 0.1327 & -0.1343 & -0.0021 \\
PGM-1 & -0.0655 & 0.0146 & -0.1064 & -0.0413 \\
PGM-2 & 0.0570 & 0.0176 & 0.0476 & 0.0653 \\
GDH & -0.1028 & 0.0140 & -0.0885 & -0.0873 \\
PHI & -0.1145 & 0.0289 & -0.1011 & -0.0823 \\
Mean & -0.1069 & 0.0411 & -0.0964 & -0.0615
\end{tabular}

five loci (PER, CE, GDH, PGM-1, PHI) there are excesses of heterozygotes within clusters. For the other two loci (FE, PGM-2) there are slight deficiencies. The $F_{S T}$ values are also highly variable from one locus to the next. As expected, the two loci with the highest levels of $F_{S T}$ (CE and FE) are also the loci whose allele frequencies are most heterogeneous among clusters (table 1). $F_{I T}$ values are also highly variable between loci, and they are negative for the same loci which show negative $F_{I S}$ values. This reflects 
excesses of heterozygotes in the whole population over frequencies predicted under Hardy-Weinberg expectations. The partitioning of the genetic variability into within and among-groups components using two methods is presented in table 4 . Both methods show that most of the variability is found within groups. The mean proportion for the seven loci using $H$ is 95.7 per cent, and the mean proportion using the Nei (1977) method is 95.8 per cent.

\section{TABLE 4}

Partitioning of genetic variability in a population of ponderosa pine. Two methods are used. The Shannon Information Index, H(Lewontin, 1972) and Nei's (1977) modification of F-statistics. See text for methods of calculations. $H_{\text {pop }}$ represents the $H$ value for the whole population and $\bar{H}_{\mathrm{grp}}$ represents the mean $H$ of all six groups. $H_{S}$ and $H_{T}$ represent the proportions of heterozygotes within groups and for the whole population respectively. $G_{S T}$ is the amount of genetic variation among groups

\begin{tabular}{|c|c|c|c|c|c|c|}
\hline \multirow[b]{2}{*}{ Locus } & \multicolumn{3}{|c|}{ Shannon Index } & \multicolumn{3}{|c|}{ Nei method } \\
\hline & $\begin{array}{l}\text { Total } \\
H_{\text {pop }}\end{array}$ & $\bar{H}_{\mathrm{grp}}$ & $\begin{array}{c}\% \text { within } \\
\text { groups }\end{array}$ & $H_{S}$ & $H_{T}$ & $G_{S T}$ \\
\hline PER & 0.970 & 0.961 & $99 \cdot 1$ & 0.387 & 0.418 & 0.051 \\
\hline $\mathrm{FE}$ & $1 \cdot 270$ & 1.266 & $96 \cdot 5$ & 0.516 & 0.528 & 0.023 \\
\hline $\mathrm{CE}$ & 1.020 & 0.970 & $95 \cdot 1$ & 0.402 & 0.412 & 0.024 \\
\hline PGM-1 & 0.350 & 0.327 & 93.4 & 0.118 & $0 \cdot 130$ & 0.092 \\
\hline PGM-2 & 0.480 & 0.445 & $92 \cdot 7$ & 0.146 & $0 \cdot 148$ & 0.014 \\
\hline PHI & $0 \cdot 170$ & 0.144 & $84 \cdot 7$ & 0.042 & $0 \cdot 045$ & 0.067 \\
\hline GDH & 0.890 & 0.878 & $98 \cdot 6$ & 0.412 & 0.420 & 0.019 \\
\hline
\end{tabular}

(ii) Genetic variation in time

The distribution of ages for the whole population (fig 2a) shows that there are quite a few old trees, that most trees have become established between about 1910 and 1930, and since then very few trees have become established. The population was divided into four major age classes:

(1) the oldest trees which includes individuals between 84 and 265 years of age;

(2) the first major group to get established, trees between 65 and 77 years old;

(3) the second major group to get established, trees between 55 and 64 years old;

(4) trees which came in after the peak of establishment for this population, and which are now 38-54 years old.

These four age classes were compared for their genetic constitutions, both in terms of allelic frequencies and the fit of genotypic frequencies to those expected at Hardy-Weinberg equilibrium. The results are presented in table 5. There are no significant differences between age classes in their allelic frequencies, and most loci are in Hardy-Weinberg equilibrium.

\section{(iii) Tree age and diameter}

The distributions of ages and diameters are quite different in the six groups (fig. 3). These differences are significant for both ages $(F=5 \cdot 57$, d.f. $=5,193 ; P<0.001)$ and diameter $(F=2.56 ;$ d.f. $=5 \cdot 193 ; P<0 \cdot 05)$. 

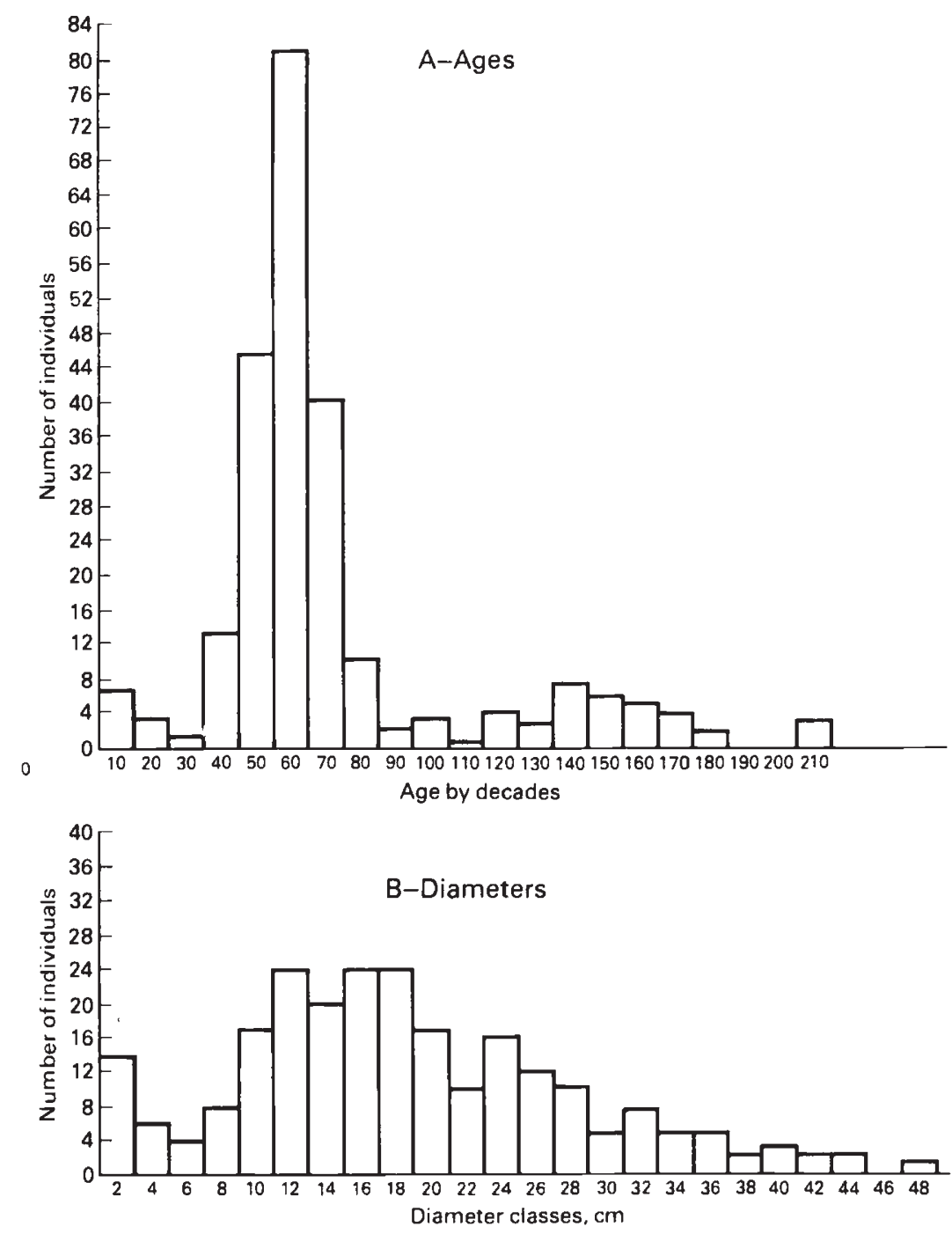

FIG. 2.-Distribution of ages (A) and diameters (B) in a ponderosa pine population.

Groups A, D, and E are striking because they have a few large, old (over 200 years) individuals which are probably the parents of the younger trees. The distributions of ages and sizes in this population do not resemble one another closely; the correlation between age and diameter is 0.62 .

\section{(iv) Cone and pollen production}

Extent of reproduction varies among the groups of trees. Differences in cone production are substantial but differences in pollen production are slight (table 6). For tests of heterogeneity, expected cone production in each group was calculated using two separate methods. The first method 
TABLE 5

Genetic characteristics of four age classes in a population of ponderosa pine. Part $\boldsymbol{A}$ is a summary of frequencies of the most common allele at seven polymorphic loci. Part $B$ is a summary of $\chi^{2}$ values obtained when testing the fit of observed genotypic frequencies to those expected under Hardy-Weinberg equilibrium for the loci with intermediate allele frequences. Most of the $\chi^{2}$ values have probabilities between 0.30 and 9.90. Whenever the probabilities approach or exceed significance at the 0.05 level, the exact probabilities are indicated

Age Classes $(N)$

A. Frequencies of most common allele \pm standard error

$\begin{array}{lccccc}\begin{array}{l}\text { Locus and } \\ \text { allele }\end{array} & 38-54(50) & 55-64(78) & 65-77(47) & 84-265(42) & \chi^{2} \\ \text { PER-2 } & 0.650 \pm 0.05 & 0.789 \pm 0.03 & 0.702 \pm 0.03 & 0.726 \pm 0.05 & 6 \cdot 27 \\ & & & & & (p<0 \cdot 1) \\ \text { FE-2 } & 0.580 \pm 0.05 & 0.596 \pm 0.04 & 0.617 \pm 0.05 & 0.679 \pm 0.05 & 2 \cdot 17 \\ \text { CE-1 } & 0.710 \pm 0.05 & 0.712 \pm 0.04 & 0.766 \pm 0.04 & 0.786 \pm 0.04 & 2.33 \\ \text { GDH-1 } & 0.710 \pm 0.05 & 0.737 \pm 0.04 & 0.638 \pm 0.05 & 0.655 \pm 0.05 & 3.47 \\ \text { PGM-1-2 } & 0.920 \pm 0.03 & 0.929 \pm 0.01 & 0.957 \pm 0.03 & 0.952 \pm 0.02 & 1.01 \\ \text { PGM-2-2 } & 0.910 \pm 0.03 & 0.904 \pm 0.01 & 0.968 \pm 0.02 & 0.881 \pm 0.03 & 4.93 \\ \text { PHI-2 } & 0.990 \pm 0.01 & 0.974 \pm 0.01 & 0.968 \pm 0.02 & 0.988 \pm 0.01 & 2.11\end{array}$

B. Fit to Hardy-Weinberg expectations

$\begin{array}{lcccc}\text { PER } & 10.05(p<0.005)^{*} & 1.50 & 1.62 & 4.22(p<0.05)^{*} \\ \text { FE } & 0.49 & 1.15 & 0.32 & 2.72(p<0.10)^{*} \\ \text { CE } & 0.19 & 0.29 & 1.06 & 0.06 \\ \text { GDH } & 0.05 & 8.78(p<0.025) \dagger & 0.52 & 0.06\end{array}$

* Excess of heterozygotes.

$\dagger$ Excess of one and deficiency of other homozygote class.

(denoted as $X^{2} A$ in table 6), consisted of calculating the mean cone production per tree by dividing the total cone production in the six groups ( 7676 in 1977 ) by 199 , the total population of trees within groups. The second method (denoted as $X^{2} B$ in table 6), involved dividing total cone production only by the total number of trees which produced cones that year (124 in 1977). As table 6 shows, the two methods yielded similar results in both years: differences between groups were highly significant. The distribution of cone production is L-shaped (fig. 4); clearly a few individuals account for most of the seed production in the population. The total cone production in the whole population in 1977 was 10,333 cones and 64 trees (29.5 per cent of the population) produced $9138(90.2$ per cent) of these cones. In 1978, the cone crop was only 700 cones, and those same individuals produced $509(72.7$ per cent $)$ cones. The same procedures were used to test for heterogeneity of pollen production. Pollen production was estimated by adding up all scores (see Materials and Methods for scoring procedures) for all trees. Differences between groups are not statistically significant.

\section{(v) Susceptibility to deer browse and woolly aphid infestation}

There are great differences between individuals in the extent of deer browse. The distribution of frequencies for 1977 is presented in fig. 5 . The distribution of deer browsing does not follow a Poisson distribution, and hence is not random since the coefficient of dispersion is much greater 

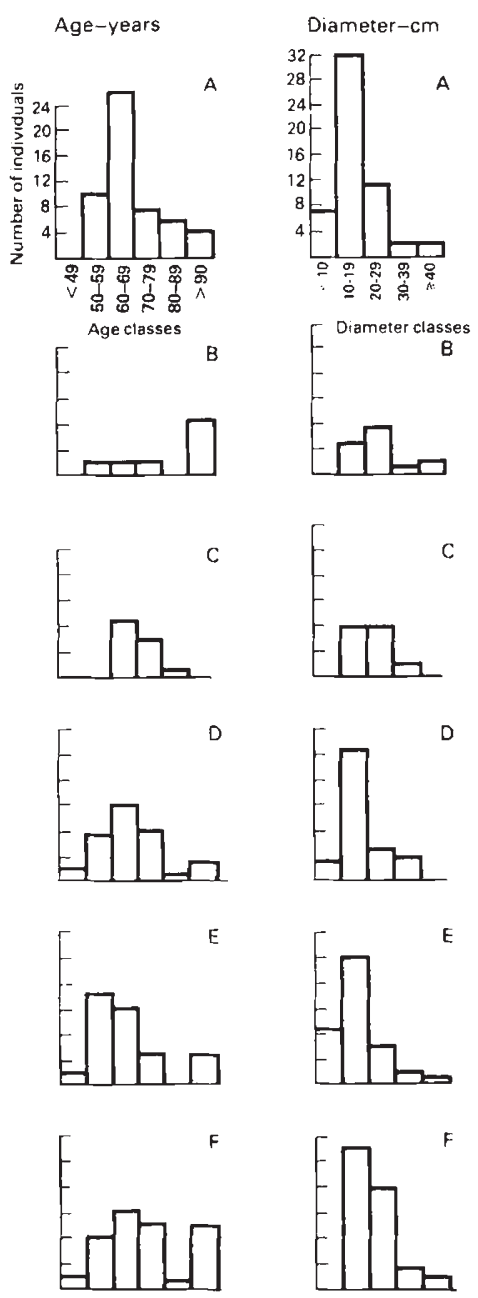

FIG. 3.-Distribution of ages and diameters in six groups within a ponderosa pine population. The groups differ significantly from one another in both age $(F=5 \cdot 57$, d.f. $=5 \cdot 193, P .<$ $0.001)$ and size $(F=2.56 ;$ d.f. $=5.193 . P<0.05)$ structure.

than 1. Correlation between 1977 browsing and 1978 browsing is $r=$ $0.629(p \ll 0 \cdot 01)$. There are also significant differences in total browsing between groups. These are presented in table 7 .

These are significant differences among clusters in the proportions of trees that are infested by woolly aphids. The proportions of trees with aphids in clusters A-F are, respectively 49 per cent, $(26 / 54), 26$ per cent (4/15), 19 per cent $(3 / 16), 15$ per cent $(5 / 33), 16$ per cent $(6 / 38)$ and 9 per cent $(4 / 43)$. In addition, FE allelic frequencies are heterogeneous between trees that are infested $(N=51)$ and those free of infestation $(N=166)$. The frequency of allele 2 is 0.500 in infested trees and 0.651 in non-infested trees $\left(\chi^{2}=6 \cdot 82, P<0 \cdot 01\right)$. 
GENETIC VARIATION IN PINE

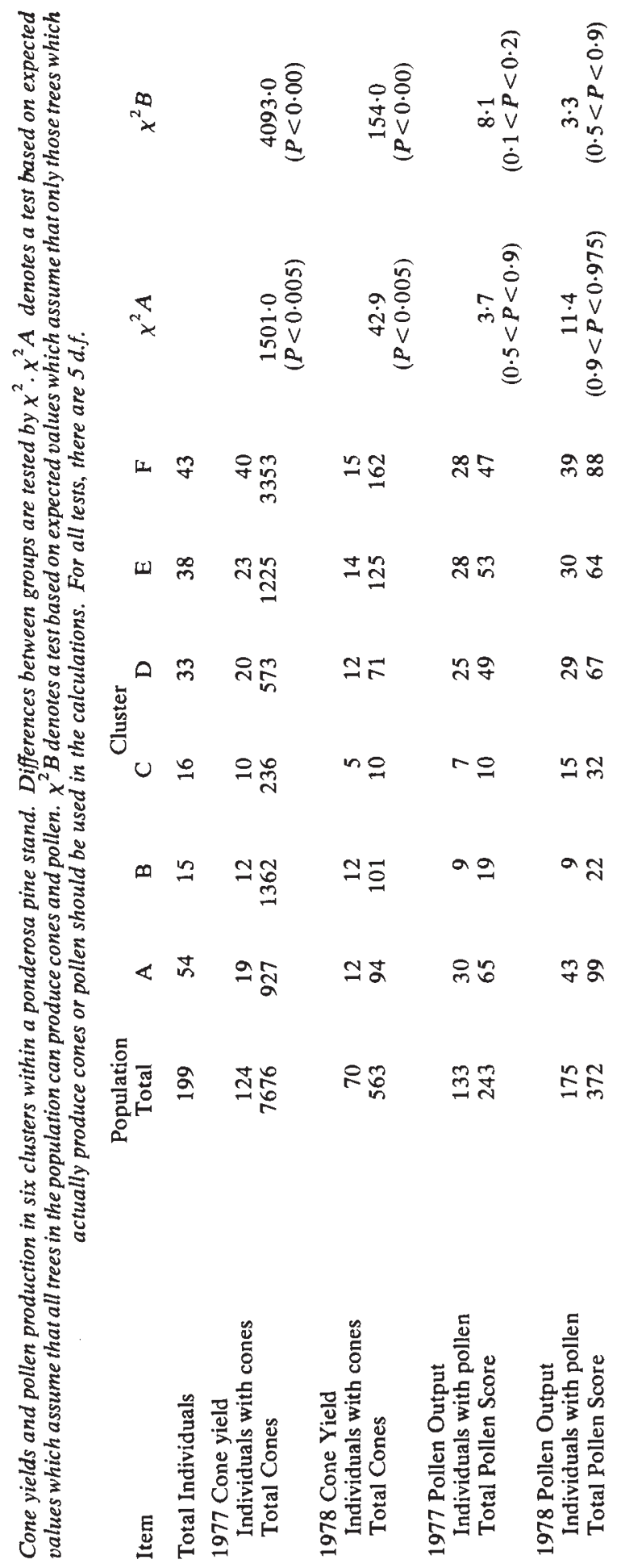



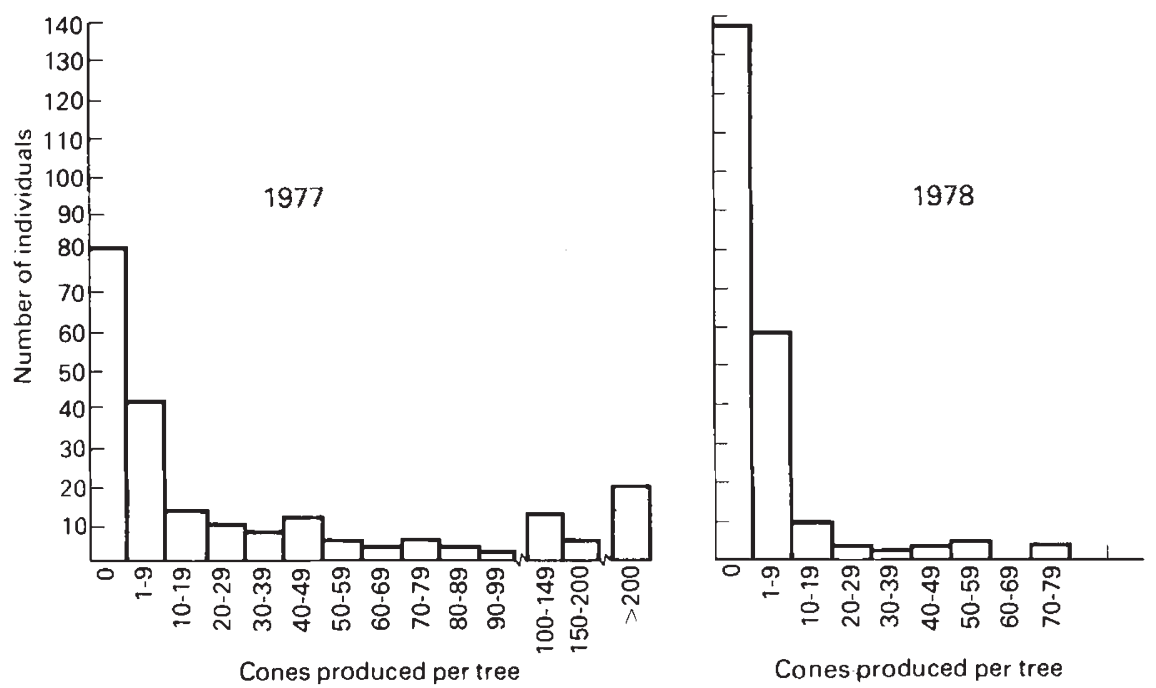

FIG. 4.-Distribution of cone production in 1977 and 1978 in a ponderosa pine population.

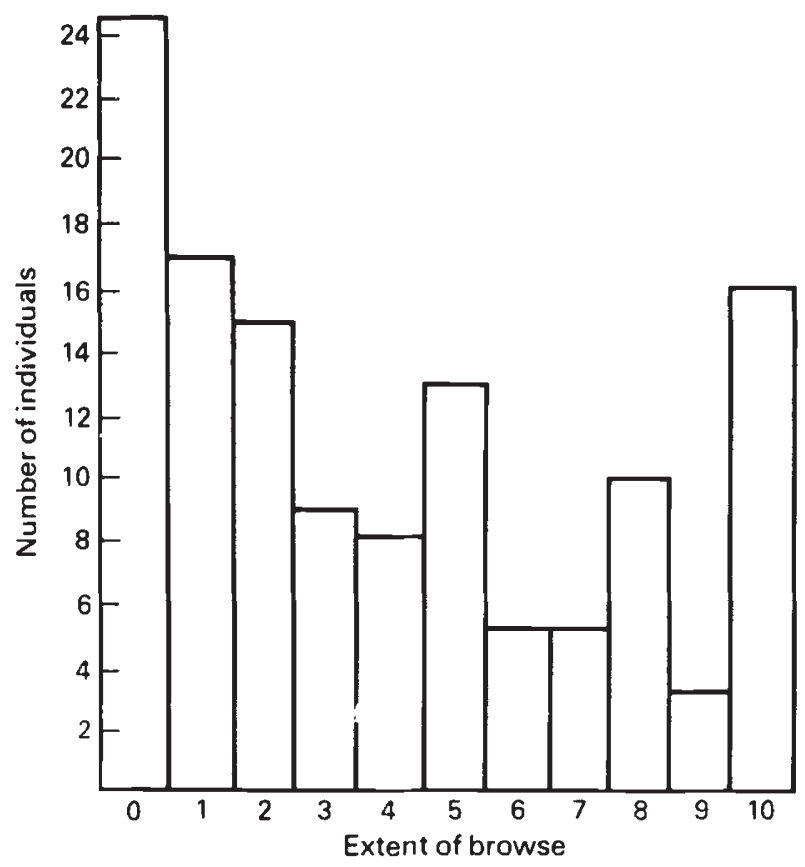

FIG. 5.-Severity of deer browsing, on a scale of 0 to 10 , in a ponderosa pine population in 1977. 
TABLE 7

Amount of deer browsing on trees accessible to deer in six clusters within a stand of ponderosa pine in 1977 and 1978. Differences were tested by $\chi^{2}$ and are significant $\left(\chi^{2}=31 \cdot 1,5\right.$ d.f. $\left.P<0.005\right)$

Item

Item

Accessible trees*

Total branches inspected 1977 and 1978

Total branches browsed Browsed

$\begin{array}{cccccc}\text { A } & \text { B } & \text { C } & \text { D } & \text { E } & \text { F } \\ 24 & 8 & 5 & 25 & 20 & 23 \\ 480 & 160 & 100 & 500 & 400 & 560 \\ 235 & 78 & 30 & 166 & 137 & 270 \\ 119 \cdot 0 & 48 \cdot 7 & 30 \cdot 0 & 33 \cdot 2 & 34 \cdot 2 & 48 \cdot 2\end{array}$

* Total trees per cluster shown here is different from totals shown in other tables because not all trees have live branches accessible to deer.

\section{Discussion}

Populations of long-lived organisms, composed of cohorts established at different times and occupying relatively large areas, can be genetically differentiated both temporally and spatially. The trees we are studying can be aged and mapped, and this has enabled us to ascertain the relative magnitudes of genetic differentiation along both these axes. When tables 1 and 5 are compared, it is clear that the genetic differentiation among spatially discrete groups is much more pronounced than differentiation among age classes. The same observation has been made in other populations of this species in Colorado ( $\mathrm{J}$ L Hamrick, in preparation) and in lodgepole pine, Pinus contorta (Knowles, 1980). Age-related differentiation is very subtle, and consists mostly of a few cases of deviations of genotypic distributions from Hardy-Weinberg expectations. The PER locus shows the greatest extent of age-related heterogeneity both in allelic and genotypic frequencies. There is also significant differentiation at this locus between two age classes in another, nearby population of ponderosa pine (Beckman, 1977).

We wish to draw particular attention to the genetic differentiation among groups in this population. The fact that plants often grow in single-species clusters is well known, and the presence of such clustering in forest trees has been reported in temperate (Stern and Roche, 1974) as well as tropical

TABLE 8

$F_{I S}$ values for seven polymorphic loci in six clusters within a population of ponderosa pine

\begin{tabular}{|c|c|c|c|c|c|c|}
\hline \multicolumn{7}{|c|}{ Cluster } \\
\hline Locus & A & B & C & D & $\mathrm{E}$ & $\mathrm{F}$ \\
\hline PER & $-0 \cdot 27$ & -0.77 & -0.33 & -0.77 & $-0 \cdot 36$ & $-0 \cdot 16$ \\
\hline $\mathrm{FE}$ & 0.04 & 0.29 & -0.09 & $0 \cdot 02$ & -0.06 & 0.02 \\
\hline $\mathrm{CE}$ & -0.19 & 0.09 & $-0 \cdot 27$ & -0.29 & -0.12 & -0.10 \\
\hline PGM-1 & 0.05 & $-0 \cdot 11$ & $-0 \cdot 11$ & -0.08 & $-0 \cdot 13$ & $0 \cdot 10$ \\
\hline PGM-2 & 0.07 & $-0 \cdot 11$ & 0.23 & 0.23 & 0.14 & $-0 \cdot 17$ \\
\hline GDH & 0.07 & -0.004 & 0.12 & -0.15 & -0.28 & -0.25 \\
\hline PHI & 0.02 & 0 & $-0 \cdot 15$ & 0 & -0.33 & $-0 \cdot 16$ \\
\hline ean & -0.03 & -0.09 & -0.09 & -0.15 & -0.16 & -0.13 \\
\hline
\end{tabular}


(Hubbell, 1979) ecosystems. The analysis of these clusters in terms of their population genetics has seldom been carried out. The few studies which have been done provide evidence that such clustering is associated with genetic heterogeneity. These studies include the Linanthus (Epling and Dobzhansky, 1942; Wright, 1978) and Liatris (Schaal, 1975) and forest trees (Tigerstedt, 1973; Kafton, 1977; Gan et al., 1977; Rudin et al., 1977).

In this population, the gerretic patterns reported in tables 3 and 4 show that there are significant differences in the genetic constitutions of the clusters. Intercluster differences are of a magnitude comparable to differences between ponderosa pine populations occupying very different environments (Mitton et al., 1977, 1980) or at different elevations. Values of $D$ (Nei 1972) range from 0.004 to 0.035 , with a mean of $0 \cdot 015$. This value is as large as the $\bar{D}(0 \cdot 145)$ calculated among eight populations of ponderosa pine distributed at elevations from $1740 \mathrm{~m}$ to $3000 \mathrm{~m}$ and separated from one another by distances up to $200 \mathrm{~km}$ (unpublished results). Comparisons between $D$ values obtained in different studies must be done with caution, since this measure is affected by the proportion of monomorphic loci used in the analyses. Two other published studies using only polymorphic loci are those of Levin (1977) and Lundkvist and Rudin (1977). Levin reports a mean $D$ value of 0.02 between subspecies of Phlox drummondii in Texas, and Lundqvist and Rudin report values of $D$ between 0.002 and 0.038 for native populations of Picea abies in Sweden. If populations planted in Sweden but of non-Swedish origins are included, values of $D$ range from 0.005 to 0.0111 . $F_{S T}$ values can also be used to compare levels of differentiation between populations. The mean $F_{S T}$ value in this population $(0 \cdot 098)$ is as high as $F_{S T}$ values within some subspecies of Phlox drummondii $\left(F_{S T}=0.07\right.$ to $\left.0 \cdot 22\right)$ studied by Levin (1977) in Texas. Populations of Polygonum pennsylvanicum studied in Ohio by Kubetin and Schaal (1979) have $F_{S T}=0 \cdot 12$. The $F_{S T}$ value in this population is also higher than the mean $F_{S T}$ of 0.06 calculated in adjacent subpopulations of Liatris aspera by Schaal (1975).

This population of ponderosa pine is not unique in having genetic differentiation among groups. In another population for which we have some information on dispersion and genetic constitution at three loci (PER, $\mathrm{FE}$ and $\mathrm{CE}$ ) there is also clustering, and the clusters are genetically heterogeneous at the FE locus (Linhart et al., 1980). Stands of ponderosa pine in this region often consist of small groups of individuals which differ among themselves in size and age structures. These clusters typically arise as a result of small, localized fires or other disturbances which provide a favourable site of establishment of large numbers of seedlings from one or a few nearby trees which produced a heavy seed crop that particular year (Schubert, 1974). The genetic relatedness of individuals within a given cluster can also be reinforced through several generations as a result of the small distances (a few metres) travelled by seeds and genetically-effective pollen in conifers (Levin and Kerster, 1974; Coles and Fowler, 1976; Muller, 1977). In addition, the seeds which are most likely to move short distances are from the lower portion of the crown (Levin and Kerster, 1974) and these seeds are most likely to be produced by selfing (Fowler, 1965).

Pronounced genetic heterogeneity among subpopulations is typically interpreted as being evidence for the existence of family groups. Such family 
groups, composed of genetically-related individuals often result in extensive inbreeding. Direct evidence for such inbreeding in natural populations has come from data which show that seedlings arising from pollinations between nearby, and presumably related, individuals are less vigorous, or show higher mortality, than seedlings arising from pollinations between individuals separated by greater distance. This has been documented in forest trees (Ledig, 1974; Coles and Fowler, 1976) and in herbs (Levin, 1977). Indirect evidence for inbreeding as a result of family clustering comes from significant deficiencies of heterozygotes which produce high positive values of $F$ in natural populations. For example Schaal (1975) reports $\bar{F}_{\underline{I}}$ of 0.407 and $\bar{F}_{I T}$ of 0.426 in subpopulations of Liatris. Levin reports $\bar{F}_{I S}$ ranging from 0.30 to 0.42 and $\bar{F}_{I T}$ ranging from 0.35 to 0.54 in Phlox subspecies. In fact, this deficiency of heterozygotes seems to be a characteristic of outbreeding plant species (Brown, 1979) who noted however that the deficiency is less marked in forest trees and wind-pollinated species than in herbs or animal pollinated plants. Comparable values in animals are reported by Wright (1978).

This population is remarkable in that it seems to be composed of family groups, as evidenced by the patchiness of allelic frequencies, yet there is no evidence for inbreeding either in the established trees, or in seedling progenies of those trees. In the established trees, the $\bar{F}_{I S}$ and $\bar{F}_{I T}$ are negative as a result of excesses of heterozygotes at five of seven loci tested. These excesses of heterozygotes may be due, in part, to the fact that we are sampling adult trees, and that there has been selection favouring heterozygotes in the seedling and sapling stages. But other events may have led to the results observed. One situation, pointed out by Rasmussen (1978) is that when family clusters are in fact composed of single sibships and are assumed to represent panmictic demes, then excesses of heterozygotes are likely to be observed. This is not likely in this population, primarily because, as we noted below, there is very high outcrossing in this population, hence related seedlings are at most half-sibs. Another factor which may lead to an excess of heterozygotes in a population is differential fertility among genotypes (Purser, 1966). As discussed below, we have observed differential fertility among genotypes, and a small population of individuals seems to produce the great majority of seeds in any one year. Finally, analyses of seedling progenies from several adult trees in the population show that the rate of outcrossing in this population is between 95 and 99 per cent; these trees are pollinated primarily by a pollen cloud whose allele frequencies are representative of the population as a whole rather than pollen from nearby neighbors only (Mitton et al., manuscript in preparation). A combination of these factors probably contributes to the lack of evidence for inbreeding found in this population.

The partitioning of genetic variability into within and among-groups components shows that one obtains very similar results whichever method is used (table 4). Incidentally, Nei (1977) states in his discussion of his method that $G_{S T}$ is identical to Wright's $F_{S T}$ and indeed the mean $G_{S T}$ as calculated here is 0.042 , while the $F_{S T}$ calculated in a somewhat different manner is $0 \cdot 041$. Most of the variability is within groups. This agrees with other analyses of populations of herbaceous species (Levin 1977; Kubetin and Schaal, 1979; Schaal and Smith 1980), and forest trees (Fins, 1965; Knowles, 1980) including ponderosa pine (O'Malley et al., 1979). 
Several things should also be noted about the population as a whole. The shape of the age distribution (fig. 2a) differs dramatically from age structures in populations of shorter-lived plant species which typically contain large numbers of small, immature individuals (Harper and White, 1974; Harper, 1977). Also, the correlation between age and diameter in this sample is only 0.62 and, though statistically significant $(P<0.01)$, it illustrates, as have other studies (reviewed in Harper, 1977), the imprecise relationship between size and age in forest trees. There has been one major period of establishment between 1910 and 1930, and very few trees have been established since then. This observation is consistent with previous observations on the recruitment of ponderosa pine in this region (Schubert, 1974; Beckman, 1977) and it suggests that decades may pass with heavy seed set and moderate germination success, but with little or no establishment of new individuals. The fact that a small proportion of the population accounted for most of the cone output in 1977 and 1978 is important, as it suggests that most of the reproduction is done by a small proportion of the trees which may well be the same, year after year. This is genetically important since we have shown (Linhart et al., 1979, 1980) that highly fertile individuals of this population are significantly different genetically from non-fertile ones at three of the seven loci used in this study. Other evolutionary consequences of such fertility patterns are also discussed by Stern and Roche (1974) and Levin and Wilson (1978).

In conclusion, the complex genetic architecture differentiation we have described is worthy of interest for several reasons. Our data demonstrate that long-lived, highly outcrossed species growing in continuous stands, can be genetically heterogeneous on a very small geographic scale. There is also some age-related heterogeneity, but it is much less pronounced. These results are consistent with those obtained in lodgepole pine. Results presented here also have ramifications for the design of sampling schemes for plant population biologists. If one is interested in sampling and selecting for a single, specific character, such as seed ouput, then, collecting from specific, highly fertile individuals and their neighbours may be appropriate since the individuals within a given neighborhood are likely to be genetically related. However, if a more complete sample of a given gene pool is required, then care must be taken to sample individuals distributed some minimum distance from one another to reduce the probability of collecting near relatives. This is particularly critical in studies which compare patterns of genetic variation among populations.

Finally, the manner in which this spatial differentiation arose warrants some speculation. As noted earlier, it is probably a reflection of the fact that populations are composed of family units. These family units seem to be produced primarily by localized seed dispersal rather than by inbreeding between close relatives. However, this may not be a sufficient explanation. As noted by Wright $(1978$, p. 515) "Where differentiation is due solely to sampling drift, the $F$-statistics are inbreeding coefficients, which, in any population, tend to be the same for all neutral loci. Where there are local differences in the conditions of selection, however, the $F$-statistics differ widely among loci". Table 5 shows that indeed, $F$ values are very different from one locus to the next. Furthermore, $F_{I S}$ values vary greatly not only among loci but among clusters of trees (tables 3,8) and $F_{I T}$ shows differences in values when it is calculated directly and indirectly (table 5). 
These observations suggest that a variety of selective forces may have acted differentially over the original groups to produce the complex mosaic observed today. This genetic mosaic in turn is associated with patchy cone production, aphid distribution and deer browsing.

Acknowledgements.-This project is supported by the U.S. National Science Foundation (grants BMS 7514050 and DEB 78.16798) and by institutional grants from the University of Colorado. We thank D. Bowman, J. Beckman, L. Jacobson, J. Logan, C. Nilon and S. Williams for technical assistance. J. Antonovics, N. Fowler, C. Gliddon, M. Grant, P. Knowles, B. Rathcke and $\mathrm{R}$. Whelan provided valuable comments on earlier drafts of the manuscript. Cooperation with $\mathrm{J}$. Hamrick has been valuable in many phases of this work. The School of Plant Biology, University College of North Wales, Bangor, provided a hospitable environment for Y.B.L. during the preparation of the manuscript.

\section{REFERENCES}

BECKMAN, J. S. 1977. Adaptive peroxidase allozyme differentiation between colonizing and established populations of Pinus ponderosa Laws. on the Shanahan Mesa, Boulder, Colorado. M.A. Thesis, University of Colorado.

BRADSHAW, A. D. 1972. Some evolutionary consequences of being a plant. Evol. Biol., 5 , 25-47.

BRown, A. H. D. 1979. Enzyme polymorphism in plant populations. Theor. Pop. Biol. 15, $1-42$.

COLES, J. F., AND FOWLER, D. P. 1976. Inbreeding in neighbouring trees in two white spruce populations. Silvae genetica, 25, 29-34.

EHRLICH, P. R., WHITE, R. R., SINGER, M. C., MCKECHNIE, S. W., AND GILBERT, L. E. 1975. Checkerspot butterflies: a historical perspective. Science, 188, 221 - 228.

ENDler, J. A. 1977. Geographic variation, speciation and clines. Princeton Univ. Press, Princeton.

EPLING, C., AND DOBZHANSKY, T. 1942. Genetics of natural populations. VI. Microgeographical races in Linanthus parryae. Genetics, 27, 317-332.

FINS, L. 1965. Genetic architecture of giant sequoia. Ph.D. Dissertation. University of California, Berkeley. 255 pps.

FOWLER, D. P. 1965. Effects of inbreeding in red pine, Pinus resinosa Ait. III. Factors affecting natural selfing. Silvae Genetica, 14, 37-46.

GAN, Y. Y., ROBERTSON, F. W., AND ASHTON, P. S. 1977. Genetic variation in wild populations of rain-forest trees. Nature, 269, 323-24.

HAMRICK, J. L., LINHART, Y. B., AND MITTON, J. B. 1979. Relationships between life history characteristics and electrophoretically-detectable genetic variation in plants. Ann. Rev. Ecol. Syst., 10, 173-200.

HARPER, J. L. 1977. Population Biology of Plants. Academic Press, New York.

HARPER, J. L., AND White, J. 1974. The demography of plants. Ann. Rev. Ecol. Syst., 5, 419-463.

HUBBELL, S. 1979. Tree dispersion, abundance and diversity in a tropical dry forest. Science, 203, $1299-1309$.

JONES, J. S. 1973. Ecological genetics and natural selection in molluscs. Science, 182, 546-551.

KAFTON, 1977. Isozyme variability and reproductive phenology of Monterey cypress. Ph.D. Dissertation, University of California, Berkeley.

KNOWLES, M. H. 1980. Genetic variation of lodgepole pine over time and microgeographic space. Ph.D. Dissertation. University of Colorado.

KUBETIN, W. R., AND SCHAAL, B.A. 1979. Apportionment of isozyme variability in Polygonum pensylvanicum (Polygonaceae). Syst. Bot., 4, 148-156.

LEDIG, F. T. 1974. An analysis of methods for the selection of trees from wild stands. Forest Science, 20, 2-18.

LEVIN, D. A. 1977. The organization of genetic variability in Phlox drummondii. Evolution, 31, $477-494$.

LEVIN, D. A., AND KERSTER, H. W. 1974. Gene flow in seed plants. Evol. Biol., 7, 179-220.

LEVIN, D. A., AND WILSON, J. B. 1978. The genetic implications of alternate adaptation in plants. In Structure and Functioning of Plant Populations, eds A. H. J. Freysen and J. W. Woldendorp pp. 75-100. North Holland Publishing Co., Amsterdam. 
LEWONTIN, R. 1972. The apportionment of human diversity. Evol. Biology, 6, 381-398.

LEWONTIN, R. 1974. The Genetic Basis of Evolutionary Change. Columbia Univ. Press, New York.

LI, C. C. 1969 . Population subdivision with respect to multiple alleles. Ann. Human Genet., London 33, 23-29.

LINHART, Y. B., MITTON, J. B., BOWMAN, D. M., STURGEON, K. B., AND HAMRICK, J. L. 1979. Genetic aspects of fertility differentials in ponderosa pine. Genet. Research, 33, 237-249.

LINHART, Y. B., MITTON, J. B., STURGEON, K. B., AND DAVIS, M. L. 1980. An analysis of genetic architecture in populations of ponderosa pine. In Isozymes of North American Forest Trees and Forest Insects. ed. M. T. Conkle, U.S. Forest Service. In Press.

LUNDKVIST, K., AND RUDIN, D. 1977. Genetic variation in 11 populations of Picea abies in Sweden as determined by isozyme analysis. Hereditas, 85, 67-74.

MITTON, J. B., LINHART, Y. B., HAMRICK, J. L., AND BECKMAN, J. S. 1977. Population differentiation and mating system in ponderosa pine of the Colorado Front Range. Theor. Appl. Genet., 51, 5-13.

MITTON, J. B., LINHART, Y. B., STURGEON, K. B., AND HAMRICK, J. L. 1979. Allozyme polymorphisms detected in mature needle tissues of ponderosa pine. Jour. Hered., 70 , 86-89.

MITTON, J. B., STURGEON, K. B., AND DAVIS, M. L. 1980. Genetic differentiation in ponderosa pine along a steep elevational transect. Silvae Genetica (in press).

MUlleR, G. 1977. Cross-fertilization in a conifer stand inferred from enzyme gene-markers in seeds. Silvae Genet., 26, 223-226.

NEI, M. 1965. Variation and covariation of gene frequencies in subdivided populations. Evolution, 19. 256-258.

NEI, M. 1972. Genetic distances between populations. Amer. Natur., 106, 283-292.

NEI, M. 1977. $F$-statistics and analysis of gene frequency in subdivided populations. Ann. Human Genet. London, 41, 225-233.

O'MALley, D. M., Allendorf, F. W., AND BLAKE, G. M. 1979. Inheritance of isozyme variation and heterogeneity in Pinus ponderosa. Biochem. Genet., 17, 233-250.

PURSER, A. F. 1966. Increase in heterozygote frequency with differential fertility. Heredity, $21,322-327$.

RASMUSSEN, D. I. 1978. Sibling clusters and genotypic frequencies. Amer. Natur., 113, 948-951.

RUDIN, D., ERIKSSON, G., AND RASMUSON, M. 1977. Inbreeding in a seed tree stand of Pinus sylvestris L. in northern Sweden. A study by the aid of the isozyme technique. Inst. for Skogsgenetik Res. Note No. 25.

SCHAAL, B. 1975. Population structure and local differentiation in Liatris cylindracea. Amer. Nat., 109, $511-528$.

SCHAAL, B. A., AND SMITH, W. G. 1980. The apportionment of genetic variation within and among populations of Desmodium nudiflorum. Evolution, 34, 214-221.

SElANDER, R. K., YANG, S. Y., AND HUNT, W. G. 1969. Polymorphism in esterases and hemoglobins in wild populations of the house mouse. Studies in Genetics, 5, 271-328. University of Texas, Austin.

SCHUBERT, G. H. 1974. Silviculture of ponderosa pine in the Southwest. United States Dept. Agric. Forest Service Res. Paper No. RM-123.

SOKAL, R. R., AND ROHLF, F. J. 1969. Biometry. 776 pp. Freeman \& Co., San Francisco. STERN, K., AND ROCHE, L. 1974. Genetics of forest ecosystems. Springer Verlag, Berlin.

TIGERSTEDT, P. M. A. 1973. Studies on isozyme variation in marginal and central population of Picea abies. Hereditas, 75, 47-60.

WORKMAN, P. L., AND NISWANDER, J. D. 1970. Population studies on southwestern Indian tribes. II. Local differentiation in the Papago. Amer. J. Human Genet., 22, 24-49.

WRIGHT, S. 1951. The genetical structures of populations. Ann. Engenics, 15, 323-354.

WRIGHT, S. 1965. The interpretation of population structure by $F$-statistics with special regard to systems of mating. Evolution, 19, 358-420.

WRIGHT, S. 1978. Evolution and the genetics of populations. Vol. 4. Variability within and among natural populations. $580 \mathrm{pp}$. University of Chicago Press, Chicago. 